\title{
Enlargement from Nadir
}

National Cancer Institute

\section{Source}

National Cancer Institute. Enlargement from Nadir. NCI Thesaurus. Code C156593.

An increase in size, volume, or quantity in comparison to nadir. 